\title{
Establishment of a Bovine Adenovirus Type 3 (BAV3)- Transformed Hamster Cell Line and Characterization of BAV3-Tumor Associated Surface Antigens
}

\author{
Shuichi Ikeyama, Yasuhiko Niiyama and Masao Takeuchi \\ Biotechnology Laboratories, Central Research Division, Takeda Chemical Indus- \\ tries, Ltd., Yodogawa-ku, Osaka 532, Japan
}

\begin{abstract}
A clonal cell line of transformant, BHKT73, was isolated from BHK21/13 cells infected with bovine adenovirus type 3 (BAV3). BHKT73 cells showed characteristics typical of transformed cells, including the ability to grow in $1.3 \%$ methylcellulose, high agglutinability with lectins, and unclear cytoplasmic microtubular fibers. Cot analysis showed that BHKT73 cells were contain BAV3 DNA.

Tumor-associated surface antigens (TASAs) of BHKT73 cells, and TrD-5 and TrJE-6 cells (A31 cells transformed by BAV3 DNA fragments with respective map units of 3.6-19.7 and 0-11.9) were studied by the protein A binding assay with rabbit anti-BHKT73 IgG, BALB/c mice anti-BHKT73 antiserum and BALB/c mice anti-TrD-5 and TrJE- 6 antisera. All these antisera bound to the surfaces of BHKT73, TrD-5 and TrJE- 6 cells, but not to the surfaces of SV40- and murine sarcoma virus-transformed A31 cells. They also bound to the surface of polyomavirus-transformed cells (pyBHK and PV-4). After absorption with pyBHK cells, these antisera showed decreased ability to bind to the surfaces of BHKT73, TrD-5, PV-4 and pyBHK cells. These results indicate that all the genetic information of BAV3 that is required for the expression of BAV3-TASAs is included between the map units of 3.6 and 11.9 on the BAV3 gene, and that BAV3-TASAs may have antigenic determinant site(s) common to one of the TASAs on polyomavirus-transformed cells.
\end{abstract}

Transformed cells have characteristics that differ from those of their normal counterparts. These characteristics include 1) alteration of morphology; 2) change in cytoskeletal system, including the decrease of cytoplasmic microtubular fibers and the disappearance of actin cables or stress fibers $(3,8,17,33) ; 3)$ increase in the degree of agglutination with lectins $(6,21,29)$; 4) release of a plasminogen activator $(31$, $39)$; 5) loss of anchorage-dependent growth control; 6) increase in the nutrient uptake $(13)$; 7) blockage of glycolipid synthesis $(12)$; 8) decrease of large external transformation-sensitive protein (LETS protein) (16) [also called cell surface protein (CSP)

Abbreviations used: BAV3, bovine adenovirus type 3; TASAs, tumor-associated surface antigens; MuSV, murine sarcoma virus; MEM, minimum essential medium; FBS, fetal bovine serum; Con A, concanavalin A; WGA, wheat germ agglutinin; RCA, caster bean agglutinin; WFA, Wistaria floribunda agglutinin; PBS, phosphate-buffered saline; HEPES, N-2-hydroxyethylpiperazine- $\mathrm{N}^{\prime}-2$ ethanesulfonic acid; DOC, sodium desoxycholate; NP-40, nonidet P-40; SDS, sodium dodecyl sulfate. 
(42) or galactoprotein A (10); 9) increase of $100 \mathrm{~K}$ protein or glucose regulated protein $(2,35)$ and 10$)$ expression of tumor-associated surface antigens (TASAs) including viral specific antigens serologically distinguishable from each other and detected among different species, and the host-derived antigens on their surface $(14,24,41)$.

The majority of these characteristics associated with transformation seem to be related to alterations in the cell surface. Therefore, a comparison of the characteristics of the cell surface of virus-transformed cells and parental normal cells is important for determining the functions and roles of cell surface components, including TASAs. It is also important to know the nature of the TASAs in order to determine the mechanism of transformation so that cancers can be treated immunologically. Thus, the TASAs of SV40-, polyomavirus-, human adenovirus- and Rous sarcoma virus-transformed cells have been studied $(14,24,41)$.

The characters of the TASAs on bovine adenovirus type 3 (BAV3)-transformed cells, however, have not been studied. Therefore, we obtained a BAV3-transformed hamster cell line (BHKT73) and prepared antisera against the transformant. Other antisera also were obtained from syngeneic BALB/c mice by immunizing them with TrD-5 and TrJE-6 cells (A31 cells transformed by BAV3 DNA fragments with respective map units of 3.6-19.7 and 0-11.9). Using these antisera, we analyzed the characters of BAV3- and its DNA fragment-transformed A31 cells (19).

\section{MATERIALS AND METHODS}

Cells and virus. A31 (a clone derived from mouse BALB/3T3 cells); SA-26 (A31 cells transformed by SV40); N-7 [A31 cells transformed by murine sarcoma virus (MuSV)]; PV-4 (A31 cells transformed by polyomavirus) and pyBHK (BHK21/13 cells transformed by polyomavirus) cells were obtained from Dr. A. Hakura (Osaka University, Osaka, Japan). BHK21/13 (an established cell line from syrian hamster kidney) cells were purchased from Flow Laboratories Inc. (Rockville, Md., U.S.A.). WT-51, TrD-5 and TrJE-6 cells (A31 cells transformed by BAV3 or its DNA fragments) were established in our laboratories (19). A clonal virus, BAV3-1, which originated from a BAV3 prototype (WBR-1) (7) was purified by $\mathrm{CsCl}$ density gradient centrifugation (26). Cells were cultured in Eagle's minimum essential medium (MEM) supplemented with 10\% fetal bovine serum (FBS; Flow Laboratories Inc.) and $100 \mu \mathrm{g} / \mathrm{ml}$ of kanamycin (Takeda Chemical Industries, Ltd., Osaka, Japan).

Colony formation in methylcellulose. The method of Risser and Pollack (34) was used to examine the growth of cells in methylcellulose. Briefly, cells were suspended in MEM containing $10 \%$ FBS and $1.3 \%$ methylcellulose $(4,000 \mathrm{cps}$, Wako Pure Chemical Industries Ltd., Osaka, Japan) at $5 \times 10^{2}$ to $10^{5}$ cells per ml. This suspension was overlaid on a $1.0 \%$ agar layer (purified agar, Difco Laboratories, Detroit, U.S.A.) containing MEM supplemented with $10 \%$ FBS. After 9 days of incubation at $37^{\circ} \mathrm{C}$, the number of colonies were counted.

Cell agglutination by lectins. Concanavalin A (Con A), wheat germ agglutinin (WGA), caster bean agglutinin (RCA) and Wistaria floribunda agglutinin (WFA) were purified by the established methods $(1,23,37)$. The method of Tsuda et al. (37) was used in the cell agglutination assays.

Morphology of cytoplasmic microtubules. The method of Weber et al. (40) was used to stain BHK21/13 and BHKT73 cells with anti-porcine tubulin rabbit IgG and fluoresceinconjugated anti-rabbit IgG goat antibodies (Microbiological Associates Inc., U.S.A.) as described previously $(20,30)$.

Cot analysis. The method of Britten and Kohne (4) was used in the reassociation kinetics 
experiments as described previously (27). The method of Gelb et al. (11) was used to determine the copy number of viral DNA in a cells.

Preparation of antibodies. 1) Rabbit anti-BHKT73 IgG. BHKT73 cells harvested with a $0.02 \%$ EDTA solution were washed with phosphate-buffered saline (PBS), pH 7.2, then injected into rabbits intravenously at a dose of $2 \times 10^{7}$ cells per rabbit. Injections were made 4 to 5 times at one-week intervals. One week after the last injection, the animals were bled to obtain anti-BHKT73 antisera. The purified IgG of the antiserum was prepared by DEAEcellulose column chromatography (9). The IgG was passed through a sterile Millipore filter (HA type, Niohn Millipore Ltd., Osaka, Japan).

2) BALB/c mice anti-BHKT73 antiserum. BHKT73 cells $\left(1\right.$ to $\left.2 \times 10^{6}\right)$ also were injected into 9-week-old male BALB/c mice intraperitoneally at intervals of 3 to 5 days for 4 weeks. One week after the last injection, the animals were bled to obtain the antiserum. Antisera from 4 to 6 mice were pooled and passed through a sterile Millipore filter.

3) BALB/c mice anti-TrD-5 and TrJE-6 antisera. The antisera were obtained from BALB/c mice immunized by subcutaneous injections of fixed transformed cells or by subcutaneous implantation of viable transformed cells. Hyperimmunization of mice was carried out as follows. Confluent or subconfluent TrD- 5 cells were killed by treating them with 30 $\mu \mathrm{g} / \mathrm{ml}$ of mitomycin $\mathrm{C}$ at $37^{\circ} \mathrm{C}$ for $40 \mathrm{~min}$, after which they were harvested with a $0.02 \%$ EDTA solution and washed with PBS. The treated cells were fixed with $0.5 \%$ paraformaldehyde in PBS at $37^{\circ} \mathrm{C}$ for $20 \mathrm{~min}$ then washed with PBS and injected into 8-9-week-old male mice. Injections ( $2 \times 10^{6}$ cells) were made 6 to 8 times at intervals of 3 to 7 days, and the mice were bled one week after the last injection. BALB/c mice (9-10-week-old male) were implanted subcutaneously with viable TrJE- 6 cells $\left(10^{6}\right.$ cells $)$. After 4 weeks, these tumorbearing mice were bled.

Absorption of antisera. Antisera diluted with medium A [MEM containing 4\% FBS and $5 \mathrm{mM}$ HEPES buffer (pH 7.2)] was absorbed prior to the binding assay by incubating the antisera at $37^{\circ} \mathrm{C}$ for $15 \mathrm{~min}$ with monolayer cells grown on a Falcon dish (Oxnard, U.S.A.), then the absorbed antisera were passed through Millipore filters. Large scale absorption with BHK21/13 cells was performed with cells grown on a roller bottle.

Binding assay of ${ }^{125}$ I-labeled protein A. Protein A (Pharmacia, Uppsala, Sweden) was labeled with $\mathrm{Na}^{125}$ I by the chloramin-T method (5). The labeled protein A was separated from excess reagents by gel filtration on a Sephadex G-25 column. The specific radioactivity was $12,500 \mathrm{cpm} / \mathrm{ng}$ protein. The binding assay was performed with monolayer cells grown on a flat-bottomed microtest plate (Microtest II, Falcon) by the method of Brown et al. (5).

Thirty thousand cells were seeded in each well and the plate was incubated at $37^{\circ} \mathrm{C}$ for one day in a humidified incubator under $5 \% \mathrm{CO}_{2}$ in air. The medium then was removed by aspiration, and $40 \mu \mathrm{l}$ of antiserum, control serum, or medium A was added to each well. After incubation at $37^{\circ} \mathrm{C}$ for $1 \mathrm{~h}$, the cells were washed twice, each time with $200 \mu \mathrm{l}$ of medium B [MEM containing $1 \%$ BSA and $5 \mathrm{mM}$ HEPES buffer (pH 7.2)]. ${ }^{125}$ I-labeled protein A $\left(5 \times 10^{4} \mathrm{cpm}\right.$ in $50 \mu \mathrm{l}$ of medium B) then was added to each well. After incubation at $37^{\circ} \mathrm{C}$ for $1 \mathrm{~h}$, these cells were washed twice, each time with $200 \mu \mathrm{l}$ of medium B. The cells then were dissolved in $100 \mu \mathrm{l}$ of $2 \mathrm{~N} \mathrm{NaOH}$ and transferred to a tube for measurement of radioactivity.

The binding assay was carried out in quadruplicate. Values for the radioactivities were corrected for nonspecific binding by subtracting the mean cpm of the ${ }^{125}$ I-protein A bound to target cells incubated without antiserum.

Radiolabeling and preparation of cell extracts. Cells grown on a dish (Falcon, $¥ 3002$ ) were radiolabeled by adding $1 \mathrm{ml}$ of fresh leucine-depleted MEM containing $\left[{ }^{3} \mathrm{H}\right]$ leucine (50 $\mu \mathrm{Ci} / \mathrm{ml}, 130-190 \mathrm{Ci} / \mathrm{mmol}, \mathrm{RCC}$ Amersham, England). After $3 \mathrm{~h}$ of incubation, the cells 
were rinsed 3 times with cold Tris-buffered saline (TBS) and made soluble on ice by the addition of $0.5 \mathrm{ml}$ of cell extraction buffer [0.15 M NaCl, $1 \%$ DOC, $1 \% \mathrm{NP}-40,0.1 \% \mathrm{SDS}$, $10 \mathrm{mM}$ sodium phosphate (pH 7.0) and $1 \%$ Trasylol] (15).

Immunoprecipitation. Immunoprecipitation of radiolabeled cell extracts was carried out by the method of Hutchinson et al. (15). The polyoma anti-T antiserum obtained from hamsters inoculated with polyomavirus-transformed cells was the gift of Dr. A. Hakura. The radiolabeled cell extract $(190 \mu \mathrm{l})$ was incubated for $2 \mathrm{~h}$ with $10 \mu \mathrm{l}$ of polyoma anti-T antiserum in an ice bath, then it was mixed with formalin-fixed Staphylococcus aureus bacteria ( $5 \mu 1$ packed cell volume) (22) and incubated for $16 \mathrm{~h}$. The precipitate obtained after centrifugation (Eppendorf model 5412 centrifuge) for $1 \mathrm{~min}$ was washed four times with $400 \mu \mathrm{l}$ of cell extraction buffer. Radiolabeled proteins were released from the precipitate by boiling it for $5 \mathrm{~min}$ in $40 \mu \mathrm{l}$ of buffer [0.0625 M Tris-HCl buffer (pH 6.8) containing $2 \%$ SDS, $10 \%$ glycerol, $5 \%$ dithiothreitol and $0.001 \%$ bromophenol blue]. The bacteria then were removed by centrifugation. The supernatant $(20 \mu \mathrm{l})$ was electrophoresed on a SDS-polyacrylamide slab gel according to the method of Laemmili (25). The concentration of acrylamide was $11 \%$. The gel was treated with EN ${ }^{3} H A N C E$ (New England Nuclear, U.S.A.) and exposed to XS film (Kodak, U.S.A.) after drying.

\section{RESULTS}

Isolation of BAV3-transformed BHK21/13 cells. BHK21/13 cells grown on a plastic dish were infected for $3 \mathrm{~h}$ with purified BAV3 at a multiplicity of 50 plaqueforming units per cells, then they were harvested with trypsin. A sample of the infected cells were reseeded on a plastic dish and cultured for 23 days. Based on morphology and the ability to grow in methylcellulose, eight clonal lines of transformants were isolated and selected. Of these isolates, BHKT73 cells differed most morphologically from the parental BHK21/13 cells (Fig. 1), and they grew well in methylcellulose. The detailed characteristics of BHKT73 cells were

1) Growth in methylcellulose. A comparison of the ability of BHK21/13 and BHKT73 cells to grow in methylcellulose was made at low cell density because BHK21/13 cells grew in a medium containing $1.3 \%$ methylcellulose when seeded at a high density. When seeded at $5 \times 10^{2}$ cells per ml, BHKT73 cells formed colonies well, but BHK21/13 cells formed scarcely any colonies (Table 1 ).

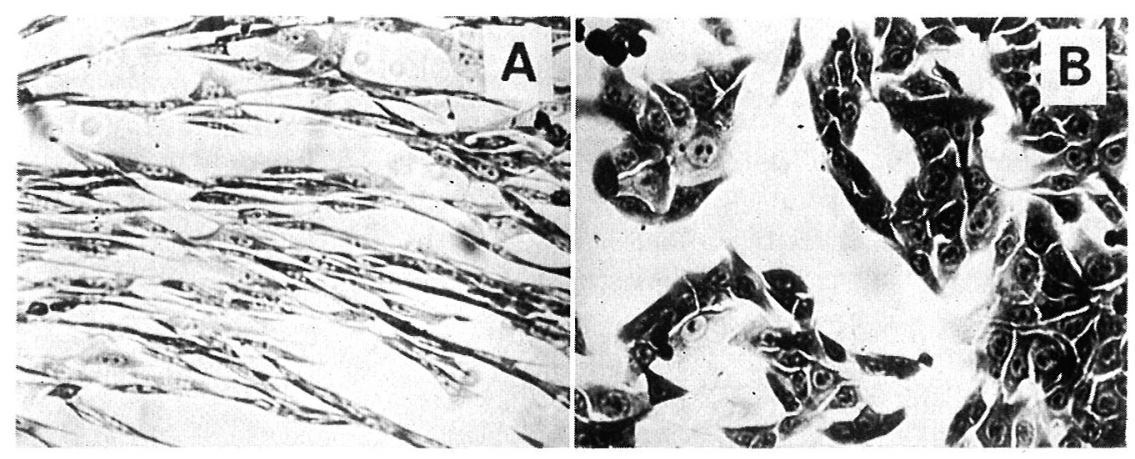

Fig. 1. Morphology of BHK21/13 and BHKT73 cells. Cells grown on a coverslip were stained with Giemsa solution. A) BHK21/13, B) BHKT73. Magnification, $\times 120$. 
TABLE 1. GROWTH OF BHK21/13 AND BHKT73 CELLS IN METHYLCELLULOSE

\begin{tabular}{ccc} 
Cell number & \multicolumn{2}{c}{ Number of colonies/plate } \\
\cline { 2 - 3 }$($ cells/plate $)$ & BHK21/13 & BHKT73 \\
$2.5 \times 10^{2}$ & 26 & 254 \\
$5.0 \times 10^{2}$ & 20 & 453 \\
$2.5 \times 10^{3}$ & 165 & 536
\end{tabular}

Cells were grown at $37^{\circ} \mathrm{C}$ in a medium containing $1.3 \%$ methylcellulose as described in the text. Colonies were counted on the 9 th day of culture.

2) Agglutination with lectins. Agglutination tests were performed with Con A, WGA, RCA and WFA. BHKT73 cells were agglutinated more easily with Con A and WFA than were BHK21/13 cells (Table 2).

3) Cytoplasmic microtubules. The networks of cytoplasmic microtubular fibers in BHK21/13 and BHKT73 cells were examined by indirect immunofluorescent staining with anti-tubulin rabbit IgG and fluorescein-conjugated anti-rabbit IgG goat antibodies. The rigidly constructed network of microtubular fibers was well stained in the cytoplasm of BHK21/13 cells, but the network in the cytoplasm of BHKT73 cells only was stained weakly (Fig. 2).

4) Viral genome. The presence of viral DNA in BHKT73 cells was determined by reassociation kinetics with ${ }^{32} \mathrm{P}$-labeled BAV3 DNA. The DNA extracted from BHKT73 cells accelerated the reassociation of ${ }^{32} \mathrm{P}$-labeled BAV3 DNA, whereas DNA from BHK21/13 cells did not (Fig. 3). In contrast, the DNAs extracted from calf thymus and hamster embryo did not accelerate the reassociation reaction, but the DNA of BHKT73 cells accelerated the reassociation of ${ }^{32} \mathrm{P}$-labeled EcoRI Dfragments (data not shown). These results mean that BHKT73 cells contained BAV3 DNA and its D-fragment, but BHK21/13 cells did not. The quantity of BAV3 DNA in BHKT73 cells was estimated from four independent experiments to be $0.83 \pm 0.22$ (mean $\pm \mathrm{SD}$ ) genome/diploid cell DNA.

Characterization of TASAs. 1) ${ }^{125}$ I-protein A binding assay. TASAs of BHKT73 cells, BAV3- and its DNA fragment-transformed A31 cells (WT-51, TrD-5 and TrJE6) were studied by the protein A binding assay. A31 cells transformed by SV40, polyomavirus and MuSV, and BHK21/13 cells transformed by polyomavirus were used

TABLE 2. AgGLUtination of BHK21/13 AND BHKT73 CELLS WITH LECTINS

\begin{tabular}{ccc}
\hline Lectin & \multicolumn{2}{c}{$\begin{array}{c}\text { Concentration of lectin required for half } \\
\text { maximum agglutination }(\mu \mathrm{g} / \mathrm{ml})\end{array}$} \\
\cline { 2 - 3 } & BHK21/13 & BHKT73 \\
Con A & 125 & 16 \\
WFA & 125 & 32 \\
WGA & 63 & 63 \\
RCA & 8 & 8
\end{tabular}

Cells were harvested from the bottles by treating them with a $0.02 \%$ EDTA solution, after which they were washed repeatedly with PBS. 

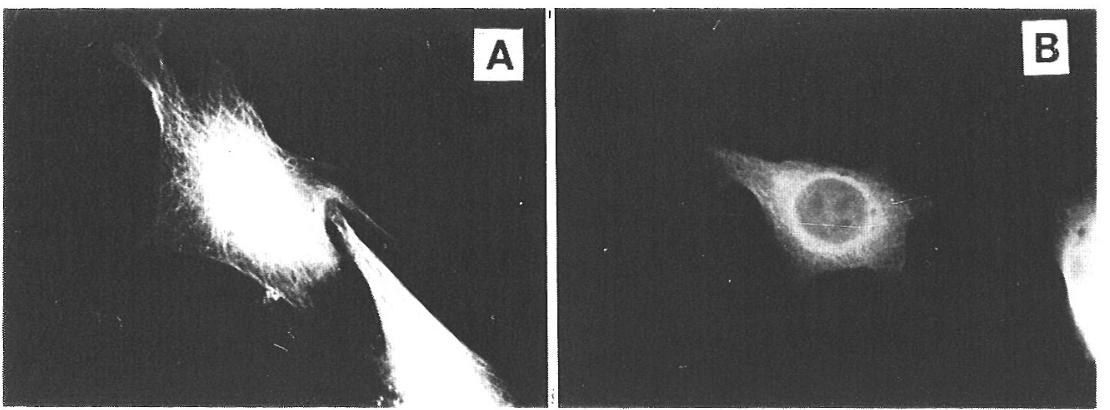

Fig. 2. Network of cytoplasmic microtubular fibers of BHK21/13 and BHKT73 cells. Cells grown on a coverslip were fixed with $3.7 \%$ paraformaldehyde in PBS and stained with rabbit antitubulin IgG and fluorescein-conjugated goat anti-rabbit IgG antibodies. A) BHK21/13, B) BHKT73. Magnification, $\times 360$.

as the controls in the analysis of BAV3-TASAs. When rabbit anti-BHKT73 IgG was used without absorption with BHK21/13 cells, it bound to the surface of all the cells tested (data not shown). After absorption with BHK21/13 cells, it bound to the surfaces of BHKT73, WT-51 and TrD-5 cells, but not to the surfaces of SA-26, N-7 and A31 cells (Table 3, first column). The control, normal rabbit serum, showed no significant binding to the cells tested (less than $50 \mathrm{cpm}$ ). Although the binding amount of ${ }^{125}$ I-protein A to each cell line differed slightly in different experiments, this was the result of different physiological conditions. Rabbit anti-BHKT73 IgG also bound to the surfaces of polyomavirus-transformed cells (pyBHK and PV-4). Similar results were obtained when BALB/c mice anti-BHKT73 antiserum was used (Table 3, second

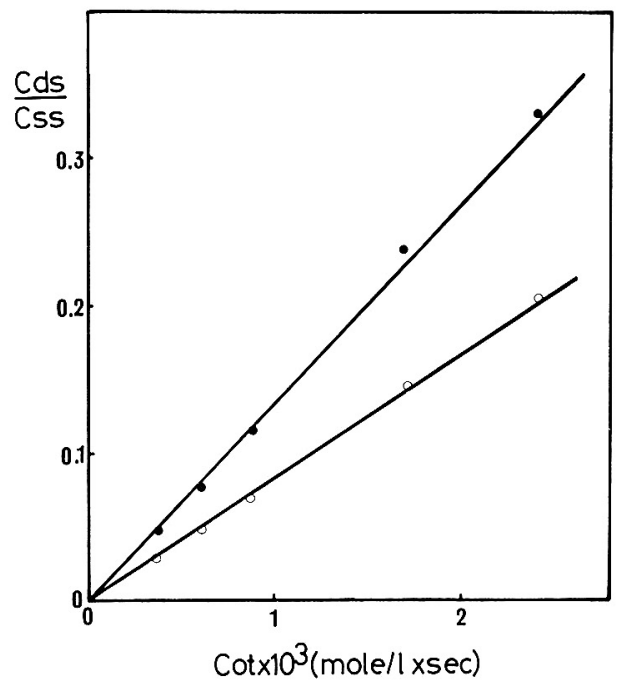

Fig. 3. Kinetics of reassociation of ${ }^{32} \mathrm{P}$-labeled BAV3 DNA in the presence of DNA obtained from BHK21/13 and BHKT73 cells. Reassociation reactions were carried out as described in the text. The reaction mixtures contained $8.4 \mathrm{ng}$ of ${ }^{32} \mathrm{P}-$ labeled BAV3 whole DNA and $1 \mathrm{mg}$ of BHK21/13 (○) or BHKT73 (•) DNA per milliliter. 
TABLE 3. BINDING OF ANTISERA TO VARIOUS CELL LINES

\begin{tabular}{|c|c|c|c|c|}
\hline \multirow{3}{*}{ Cell line } & \multicolumn{4}{|c|}{${ }^{125} \mathrm{I}$-protein A bound (mean $\mathrm{cpm} \pm$ S.D.) } \\
\hline & \multicolumn{2}{|c|}{ Anti-BHKT73 serum } & \multirow{2}{*}{$\begin{array}{c}\begin{array}{c}\text { Anti-TrJE-6 } \\
\text { serum }^{c}\end{array} \\
\text { BALB/c }\end{array}$} & \multirow{2}{*}{$\begin{array}{c}\begin{array}{c}\text { Anti-TrD-5 } \\
\text { serum }^{c}\end{array} \\
\text { BALB/c }\end{array}$} \\
\hline & Rabbit $^{\mathrm{a}}$ & $\mathrm{BALB} / \mathrm{c}^{\mathrm{b}}$ & & \\
\hline BHK21/13 & $81 \pm 10$ & $566 \pm 96$ & $-26 \pm 13$ & $-16 \pm 17$ \\
\hline BHKT73 & $465 \pm 30$ & $2465 \pm 182$ & N.T. ${ }^{d}$ & $497 \pm 46$ \\
\hline pyBHK & $230 \pm 37$ & $4683 \pm 155$ & $803 \pm 40$ & $419 \pm 45$ \\
\hline A31 & $23 \pm 19$ & $89 \pm 20$ & $8 \pm 17$ & $-2 \pm 9$ \\
\hline WT-51 & $611 \pm 74$ & $4496 \pm 287$ & $1580 \pm 156$ & N.T. ${ }^{d}$ \\
\hline TrD-5 & $652 \pm 164$ & $6916 \pm 716$ & $2087 \pm 73$ & $655 \pm 103$ \\
\hline TrJE-6 & N.T. ${ }^{\mathrm{d}}$ & $1632 \pm 78$ & $834 \pm 41$ & N.T. ${ }^{\mathrm{d}}$ \\
\hline SA-26 & $22 \pm 3$ & $-8 \pm 16$ & $5 \pm 34$ & N.T. ${ }^{d}$ \\
\hline N-7 & $61 \pm 37$ & $42 \pm 15$ & $32 \pm 34$ & $7 \pm 15$ \\
\hline PV-4 & $411 \pm 139$ & $913 \pm 83$ & $1873 \pm 110$ & N.T. ${ }^{\mathrm{d}}$ \\
\hline
\end{tabular}

a Rabbit anti-BHKT73 IgG $(10 \mu \mathrm{g} / 40 \mu \mathrm{l})$ was absorbed with $\mathrm{BHK} 21 / 13$ cells $\left(3.5 \times 10^{6}\right)$ at $37^{\circ} \mathrm{C}$ for $60 \mathrm{~min}$.

b BALB/c mice anti-BHKT73 antiserum was diluted 20-fold with medium A then absorbed with BHK21/13 cells $\left(1.6 \times 10^{6}\right)$ at $37^{\circ} \mathrm{C}$ for $60 \mathrm{~min}$.

c Anti-TrJE-6 antiserum (obtained from TrJE-6 tumor-bearing mice) and anti-TrD-5 antiserum were diluted 16-fold with medium A.

d Not tested.

column). These results indicate that the BAV3-TASAs detected with xenogeneic anti-BHKT73 antiserum have an antigenic determinant site(s) common to one of the TASAs on the surface of the polyomavirus-transformed cells.

We obtained almost the same results with syngeneic antisera. BALB/c mice were immunized by subcutaneous injections of fixed transformed cells or by subcutaneous implantation of viable transformed cells. Anti-TrJE-6 (third column, Table 3) and anti-TrD-5 (last column, Table 3) antisera bound to the surfaces of BHKT73, WT-51, TrD-5 and TrJE-6 cells, but not to the surfaces of SA-26, N-7, BHK21/13 and A31 cells. They also bound to the surfaces of pyBHK and PV-4 cells.

BALB/c mice anti-BHKT73 antiserum and TrJE-6 antiserum did not bind to the

TABLE 4. BINDING OF MOUSE ANTISERUM TO EMBRYONIC CELLS

\begin{tabular}{lccc}
\hline \multirow{2}{*}{ Serum } & Dilution rate & \multicolumn{2}{c}{${ }^{125}$ I-protein A bound (mean cpm \pm S.D.) } \\
\cline { 3 - 4 } & & TrD-5 & Embryonic cells $^{\mathrm{b}}$ \\
\hline Normal $^{\mathrm{c}}$ & 5 & N.T. & $13 \pm 13$ \\
Anti-TrJE-6 $^{\mathrm{d}}$ & 11 & $551 \pm 49$ & $1 \pm 8$ \\
Anti-BHKT73 & 50 & $934 \pm 68$ & $11 \pm 8$
\end{tabular}

a Serum was diluted with medium A.

b Secondary cultured cells of 14-day-old embryos from BALB/c mice.

c Normal BALB/c mice (14-week-old male) serum.

d Serum was obtained from TrJE-6 tumor-bearing mice.

e Not tested. 


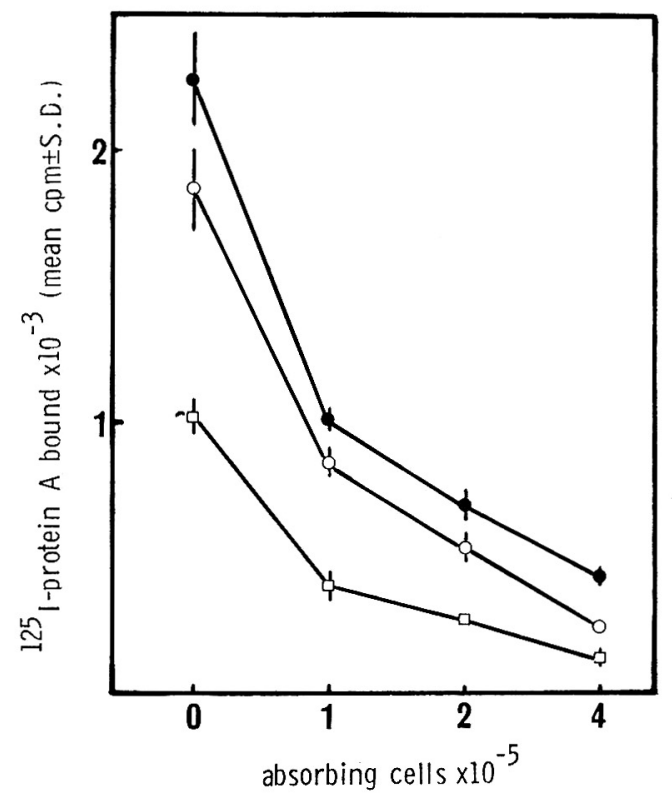

Fig. 4. Effect of absorption with pyBHK cells on binding of anti-TrJE-6 antiserum to transformed cells. Anti-TrJE-6 antiserum (obtained from TrJE-6 tumor-bearing mice) that had been diluted 16-fold with medium $A$ was absorbed with the indicated number of pyBHK cells after which its residual binding activities to TrD-5 (०), PV-4 (•) and pyBHK ( $\square$ ) cells were determined.

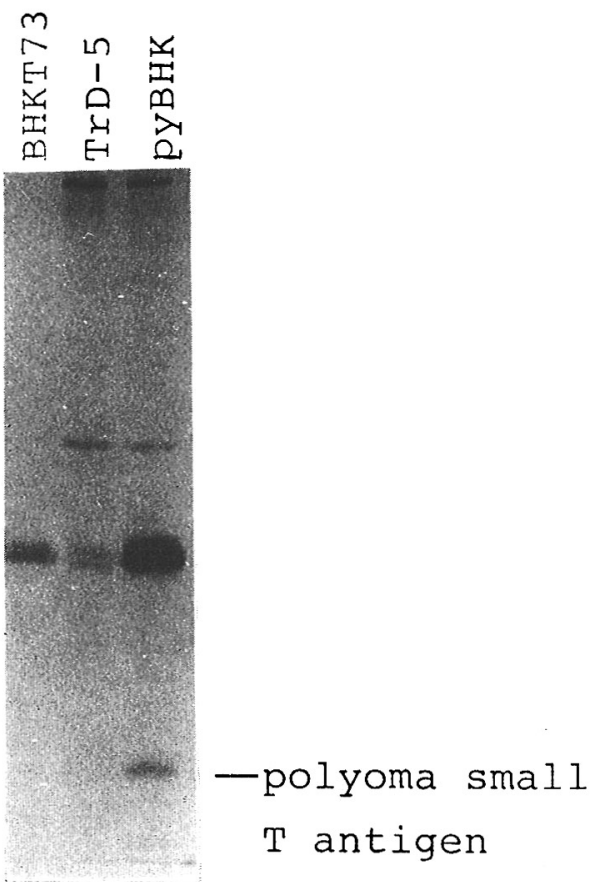

Fig. 5. SDS-polyacrylamide slab gel electrophoresis of the immunoprecipitate. Actively growing pyBHK, BHKT73 and TrD-5 cells were used for the radiolabel. The immunoprecipitates were prepared with polyoma anti-T antiserum as described in the text. 
surfaces of embryonic cells from BALB/c mice (Table 4). This indicates that the BAV3TASAs detected in this experiment are not related to embryonic antigens.

2) Absorption with pyBHK cells. BALB/c mice anti-TrJE-6 antiserum was absorbed with pyBHK cells, then its residual binding activities to TrD-5, PV-4 and pyBHK cells were determined (Fig. 4). The amount of antiserum bound to the surfaces of these cells was decreased markedly by absorption with pyBHK cells. The binding abilities of rabbit anti-BHKT73 IgG and BALB/c mice anti-BHKT73 antiserum to the surfaces of TrD-5, PV-4, BHKT73 and pyBHK cells also were decreased by absorption with pyBHK cells (data not shown).

Assay of polyoma $T$ antigen. We investigated whether the BHKT73 and TrD-5 cells had ever been super-infected by polyomavirus. Polyomavirus small $\mathrm{T}$ antigen (15) was detected in the extract of pyBHK cells, but not in the extracts of BHKT73 and TrD-5 cells (Fig. 5). These results show that BHKT73 and TrD-5 cells have never been super-infected by polyomavirus.

\section{DISCUSSION}

BHKT73 cells could grow and form colonies in medium containing $1.3 \%$ methylcellulose (Table 1). They were agglutinated with Con A and WFA (Table 2) and showed fewer and obscured cytoplasmic microtubular fibers (Fig. 2). In addition, BHKT73 cells were proved to contain BAV3 DNA and its EcoRI D-fragment. These cells also released a tumor angiogenesis factor (38) and expressed $\mathrm{T}$ antigen (28). The appearance of all the phenotypes of BHKT73 cells thus is believed to be due to transformation by BAV3.

BAV3-TASAs on BAV3-transformed cells also were found on the surfaces of TrD-5 and TrJE-6 cells, both of which were transformed from A31 cells by the EcoRI Dfragment DNA (3.6-19.7 map units) and by Hind III JE-fragment DNA (0-11.9 map units) of BAV3 DNA (19). This locus has been shown to contain genes related to T antigen (28). Clearly, all the genetic information of BAV3 required for the transformation and expression of BAV3-TASAs is located between the map units 3.6 and 11.9 on the BAV3 genome.

All the antisera used in the experiments reported here bound to the surfaces of BAV3- and its DNA fragment-transformed BHK21/13 and A31 cells, and to the surfaces of poyomavirus-transformed BHK21/13 and A31 cells as well (Table 3). These antisera did not bind to the surfaces of SA-26, N-7, BHK21/13, A31 and BALB/c mice embryonic cells (Table 3 and 4). The abilities of these antisera to bind to TrD-5, BHKT73, PV-4 and pyBHK cells were abolished after the antisera had been absorbed with pyBHK cells (Fig. 4). Polyomavirus occasionally induces superinfection in cultured cells. The cross-reactivity of the TASAs of BAV3-transformed and polyomavirustransformed cells, however, was not due to superinfection by polyomavirus in the BAV3-transformed cells because 1) polyomavirus and its DNA have never been used in our laboratories; 2) the chance of superinfection by polyomavirus is equal for every cell and there is no reason why only BAV3-transformed cells would be infected with polyomavirus; and 3) no polyomavirus small $\mathrm{T}$ antigen was detected in the extracts of BHKT73 and TrD-5 cells (Fig. 5). Therefore, we conclude that the TASAs on BAV3-transformed cells are BAV3-specific antigens which are serologically distinguishable and which have regions common to the TASAs on polyomavirustransformed cells. 
In their early work on the TASAs induced by SV40, Pancake and Mora (32) reported that antisera prepared by repeated inoculation of SV40-transformed mouse cells into syngeneic $\mathrm{AL} / \mathrm{N}$ mice could kill polyomavirus-transformed $\mathrm{AL} / \mathrm{N}$ mouse cells. They concluded that SV40 and polyomavirus transformation might result in the appearance of common cell surface antigens that differ from the embryonic antigens. The TASAs detected on BAV3-transformed cells in our experiments also were not the embryonic antigens described by other investigators $(24,36)$ (Table 4). The possibility that they are host-derived TASAs can not be completely ruled out, but our finding BAV3-TASAs with antigenic determinant site(s) common to polyomavirus-TASAs may be a clue to the function of TASAs in the process of viral transformation.

Acknowledgments. We are grateful to Dr. A. Hakura for his gift of the cell lines and polyoma anti-T antiserum used. We also thank Drs. Y. Sugino and A. Kakinuma for their helpful suggestions.

\section{REFERENCES}

1. Agrawal, B.B.L. and I.J. Goldstein. Protein-carbohydrate interaction. VI. Isolation of Concanavalin A by specific adsorption on cross-linked dextran gels. Biochim. Biophy. Acta 147, 262-271, 1967

2. Bramwell, M.E. and H. Harris. Some further information about the abnormal membrane glycoprotein associated with malignancy. Proc. R. Soc. Lond. B. 203, 93-99, 1978

3. Brinkley, B.R., G.M. Fuler and D.P. Highlield. Cytoplasmic microtubules in normal and transformed cells in culture; Analysis by tubulin antibody immunofluorescence. Proc. Natl. Acad. Sci. U.S.A. 72, 4981-4985, 1975

4. BRITTEN, R.J. and D.E. KohNe. Repeated sequences in DNA. Science 161, 529-540, 1968

5. Brown, J.P., J.M. Klitzman and K.E. Hellström. A microassay for antibody binding to tumor cell surface antigens using ${ }^{125}$ I-labeled protein A from Staphylococcus aureus. J. Immunol. Methods 15, 57-66, 1977

6. Burger, M.M. A difference in the architecture of the surface membrane of normal and virally transformed cells. Proc. Natl. Acad. Sci. U.S.A. 62, 994-1001, 1969

7. DarbyshiRe, J.H. Oncogenicity of bovine adenovirus type 3 in hamster. Nature 211, 102, 1966

8. Edelman, G.M. and I. YaHARA. Temperature-sensitive change in surface modulating assemblies of fibroblasts transformed by mutants of Rous sarcoma virus. Proc. Natl. Acad. Sci. U.S.A. 73, 2047-2051, 1976

9. FAHEY, J.L. and A.P. HoRbett. Human gamma globulin fractionation on anion exchange cellulose columns. J. Biol. Chem. 234, 2645-2651, 1959

10. Gahmberg, C.G. and S. Hakomori. Altered growth behavior of malignant cells associated with changes in externally labeled glycoprotein and glycolipid. Proc. Natl. Acad. Sci. U.S.A. 70, 3329-3333, 1973

11. Gelb, L.D., D.E. Kohne and M. Martin. Quantitation of simian virus 40 sequences in African green monkey, mouse and virus-transformed cell genomes. J. Mol. Biol. 57, 129-145, 1971

12. НАкомоRI, S. Structures and organization of cell surface glycolipids dependency on cell growth and malignant transformation. Biochim. Biophy. Acta 417, 55-89, 1975

13. Hatanaka, M. Transport of sugars in tumor cell membranes. Biochim. Biophy. Acta 355, 77104, 1974

14. Herberman, R.B. Immunogenicity of tumor antigens. Biochim. Biophy. Acta 473, 93-119, 1977

15. Hutchinson, M.A., T. Hunter and W. ECKhart. Characterization of T antigens in polyomainfected and transformed cells. Cell 15, 65-77, 1978

16. Hynes, R.O. Alteration of cell-surface proteins by viral transformation and by proteolysis. Proc. Natl. Acad. Sci. U.S.A. 70, 3170-3174, 1973

17. Hynes, R.O. and A.T. Destree. $10 \mathrm{~nm}$ filaments in normal and transformed cells. Cell 13, 
$151-163,1978$

18. Igarashi, K., Y. Nilyama, K. Tsukamoto, T. Kurokawa and Y. Sugino. Biochemical studies on bovine adenovirus typy 3. II. Incomplete virus. J. Virol. 16, 634-641, 1975

19. Igarashi, K., R. Sasada, T. Kurokawa, Y. Nilyama, K. Tsukamoto and Y. Sugino. Biochemical studies on bovine adenovirus type 3. IV. Transformation by viral DNA and DNA fragments. J. Virol. 28, 219-226, 1978

20. IKeYAMA, S. and M. TAKeUCHI. Antitubulin activities of ansamitocins and maytansinoids. Biochem. Pharmacol. 30, 2421-2425, 1981

21. InBAR, M. and L. SACHS. Interaction of the carbohydrate-binding protein concanavalin A with normal and transformed cells. Proc. Natl. Acad. Sci. U.S.A. 63, 1418-1425, 1969

22. KeSSLER, S. Cell membrane antigen isolation with the Staphylococcal protein A-antibody adsorbent. J. Immunology 117, 1482-1490, 1976

23. Kurokawa, T., M. Tsuda and Y. Sugino. Purification and characterization of a lectin from Wistaria floribunda seeds. J. Biol. Chem. 251, 5686-5693, 1976

24. Kurth, R. and H. BAUER. Avian RNA tumor viruses. A model for studying tumor-associated cell surface alteration. Biochim. Biophys. Acta 417, 1-23, 1975

25. LAEMMLI, U.K. Clevage of structural proteins during the assembly of the head of bacteriophage T4. Nature 227, 680-685, 1970

26. Nityama, Y., K. Igarashi, K. Tsukamoto, T. Kurokawa and Y. Sugino. Biochemical studies on bovine adenovirus type 3. I. Purification and properties. J. Virol. 16, 621-633, 1975

27. Nityama, Y., R. Sasada, K. Igarashi, T. Kurokawa and Y. Sugino. Biochemical studies on bovine adenovirus type 3 . V. Some properties of mouse cells transformed with viral DNA fragments. Cell Struct. Funct. 6, 121-131, 1981

28. NiIYAMA, Y. Biochemical studies on bovine adenovirus type 3. VI. Identification of virusspecific early proteins and tumor antigens. Cell Struct. Funct. 6, 133-146, 1981

29. NiCOlson, G.L. The interactions of lectins with animal cell surface. Inter. Rev. Cytol. 39, 89190,1974

30. Ootsu, K., Y. Kozai, M. Takeuchi, S. Ikeyama, K. Igarashi, K. Tsukamoto, Y. Sugino, T. Tashiro, S. Tsukagoshi and Y. Sakurai. Effects of new antimitotic antibiotics, ansamitocins, on the growth of murine tumor in vivo and on the assembly of microtubules in vitro. Cancer Res. 40, 1707-1717, 1980

31. Ossowski, L., J.C. Unkeless, A. Tobia, J.P. Quigley, D.B. Rifkin and E. Reich. An enzymatic function associated with transformation of fibroblasts by oncogenic viruses II. Mammalian fibroblast cultures transformed by DNA and RNA tumor viruses. J. Exp. Med. 137, 112-126, 1973

32. PANCAKE, S.J. and P.T. MoRA. Limitations and utility of a cytolytic assay for measuring simian virus 40-induced cell surface antigens. Cancer Res. 36, 88-94, 1976

33. Pollack, R., M. Osborn and K. Weber. Patterns of organization of actin and myosin in normal and transformed culture cells. Proc. Natl. Acad. Sci. U.S.A. 72, 994-998, 1975

34. RisSER, R. and R. Pollack. A non-selective analysis of SV40 transformation of mouse 3T3 cells. Virology 59, 447-489, 1974

35. Shiu, R.P.C., J. Pouyssegur and I. Pastan. Glucose depletion accounts for the induction of two transformation-sensitive membrane proteins in Rous sarcoma virus-transformed chick embryo fibroblasts. Proc. Natl. Acad. Sci. U.S.A. 74, 3840-3844, 1977

36. Ting, C.C., J.R. Ortaldo and R.B. Herberman. Expression of fetal antigens and tumorspecific antigens in SV-40 transformed cells I. Serological analysis of the antigenic specificities. Int. J. Cancer 12, 511-518, 1973

37. Tsuda, M, T. Kurokawa, M. TakeUChI and Y. Sugino. Changes in cell surface structure by viral transformation studied by binding of lectins differing in sugar specificity. Gann 66, 513521,1975

38. Tsukamoto, K. and Y. Sugino. Tumor angiogenesis activity in clonal cells transformed by bovine adenovirus type 3. Cancer Res. 39, 1305-1309, 1979

39. Unkeless, J.C., A. Tobia, L. Ossowski, J.P. QUigley, D.B. Rifkin and E. Reich. An enzymatic function associated with transformation of fibroblasts by oncogenic viruses I. Chick embryo 
fibroblast cultures transformed by avian RNA tumor viruses. J. Exp. Med. 137, 85-111, 1973

40. Weber, K., Th. Bibring and M. Osborn. Specific visualization of tubulin-containing structures in tissue culture cells by immunofluorescence. Exp. Cell Res. 95, 111-120, 1975

41. WeIL, R. Viral 'tumor antigens' A novel type of mammalian regulator protein. Biochim. Biophy. Acta 516, 301-388, 1978

42. YAMADA, K.M. and J.A. WeSTON. Isolation of a major cell surface glycoprotein from fibroblasts. Proc. Natl. Acad. Sci. U.S.A. 71, 3492-3496, 1974

(Received for publication, March 11, 1982) 